\title{
ИЗМЕНЕНИЕ ГЕМАТОЛОГИЧЕСКИХ И ИММУНОЦИТОХИМИЧЕСКИХ ПОКАЗАТЕЛЕЙ КРОВИ БЕЛЫХ КРЫС ПРИ ИНТОКСИКАЦИИ АЦЕТАТОМ СВИНЦА
}

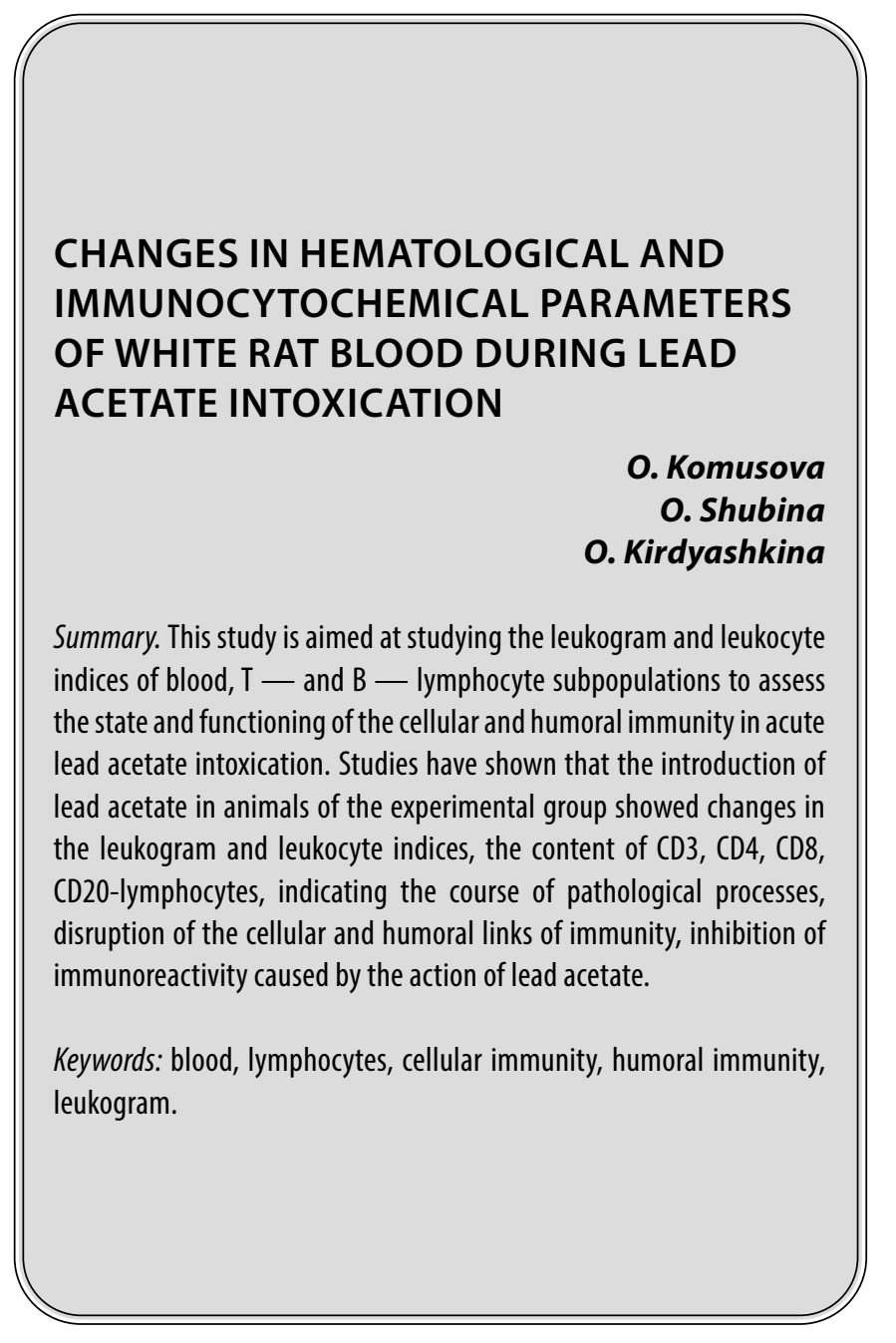

\section{Введение}

И зучение лейкоцитарного профиля в норме и при различных воздействиях является традиционным и важнейшим направлением современной гематологии. Несмотря на большое число исследований в данном направлении и с учетом выраженной защитной функции и высокой реактивности лейкоцитов периферической крови представляется целесообразным изучение их количественного содержания для оценки степени эндогенной интоксикации животного организма, клеточного и гуморального звеньев иммунитета при подостром отравлении соединениями свинца $[1,2,4]$.
Комусова Ольга Ивановна

К.б.н., ФГБОУ ВО «Мордовский государственный педагогический университет имени М.Е. Евсевьева»

(2. Саранск)

timoshkina03@mail.ru

Шубина Ольга Сергеевна

Д.б.н., профессор, ФГБОУ ВО «Мордовский государственный педагогический университет имени М.Е. Евсевьева» (2. Саранск) os.shubina@mail.ru

Кирдяшкина Ольга Викторовна Аспирант, ФГБОУ ВО «Мордовский государственный педагогический университет имени М.Е. Евсевьева»

(2. Саранск)

Sigma.ov@mail.ru

Аннотация. Данное исследование направлено на изучение лейкограммы и лейкоцитарных индексов крови, субпопуляции Т- и В- лимфоцитов для оценки состояния и работы клеточного и гуморального звена иммунитета при острой интоксикации ацетатом свинца. Исследования показали, что при введении ацетата свинца у животных опытной группы отмечались изменения, в лейкограмме и лейкоцитарных индексах, содержании CD3, CD4, CD8, CD20-лимфоцитов, указывающие на протекание патологических процессов, нарушение работы клеточного и гуморального звеньев иммунитета, угнетение иммунореактивности, вызванные действием ацетата свинца.

Ключевые слова: кровь, лимфоциты, клеточный иммунитет, гуморальный иммунитет, лейкограмма.

\section{Цель выполнения исслеАования}

Выявить закономерности изменений лейкограммы, лейкоцитарных индексов крови, оценить экспрессию субпопуляций лимфоцитов в периферической крови у крыс при подострой интоксикации ацетатом свинца.

\section{Материалы и методы исследования}

Данное исследование проведено на 50 белых беспородных половозрелых крысах-самцах, которые были разделены на 2 группы. Контрольная группа находилась на общем режиме вивария. Опытная группа получала в течение 7 суток перорально ацетат свинца 
Таблица 1. Лейкограмма крови крыс $(\mathrm{M} \pm \mathrm{s})$

\begin{tabular}{|l|l|l|}
\hline Показатель & Контроль & Опыт \\
\hline Лейкоциты, 10\%/л & $6,8 \pm 0,3$ & $7,2 \pm 0,2^{*}$ \\
\hline Палочкоядерные нейтрофилы,\% & $2,4 \pm 1,4$ & $5,6 \pm 1,0^{*}$ \\
\hline Сегментоядерные нейтрофилы,\% & $16,2 \pm 1,9$ & $17,3 \pm 0,9^{* *}$ \\
\hline Эозинофилы,\% & $3,1 \pm 1,0$ & $9,3 \pm 0,9^{*}$ \\
\hline Базофилы,\% & $1,8 \pm 0,8$ & $1,0 \pm 0,4^{*}$ \\
\hline Моноциты,\% & $4,1 \pm 1,5$ & $2,3 \pm 0,5^{*}$ \\
\hline Лимфоциты,\% & $72,3 \pm 2,6$ & $64,3 \pm 1,6^{*}$ \\
\hline
\end{tabular}

Примечание: * - достоверно по отношению к контролю $\mathrm{P} \leq 0,01$; * - достоверно по отношению к контролю $\mathrm{P} \leq 0,05$; " - достоверно по отношению к опыту $1 \mathrm{P} \leq 0,01$; \# - достоверно по отношению к опыту $1 \mathrm{P} \leq 0,05$.

$\mathrm{Pb}\left(\mathrm{CH}_{3} \mathrm{COO}\right)_{2} \times 3 \mathrm{H}_{2} \mathrm{O}$ в дозе $45 \mathrm{mг} /$ кг/сутки (в пересчете на свинец), что соответствует подострой интоксикации экспериментальных животных $[4,5]$.

В работе применялись высокоинформативные методы исследования периферической крови: гематологические, иммуноцитохимические, статистические.

Периферическую кровь получали из хвостовой вены крысы под наркозом смеси эфира с хлороформом (1:1) перед декапитацией.

Мазки крови окрашивали по методу Романовского - Гимзы. Лейкоциты подсчитывали в камере Горяева. Относительное содержание лейкоцитов определяли путем цитологического исследования мазков крови $[1,3,5]$.

Расчет индексов производился на основании данных лейкограммы.

Для получения характеристики Т-клеточного звена циркулирующих лимфоцитов оценивалась экспрессия маркеров CD3, CD4, CD8. Для оценки В-системы иммунитета (гуморального звена) определялось количество В-лимфоцитов (CD20).

Согласно инструкции фирмы производителя Dako (Дания) суспензию лимфоцитов раскапывали на стекла с лунками, предварительно обработанными 0,1\% поли-L-лизином (Serva, Германия). В каждую лунку вносили по 20 мкл клеточной взвеси в концентрации $5 \times 10 \%$ мл. Инкубировали в течение 30 мин во влажной камере. Фиксировали 70\% этиловым спиртом 10 мин. После фиксации клетки отмывали в фосфатном буфере (PBS) 3 раза по 5 мин. Далее на приготовленные клетки наносили по 20 мкл специфических моноклональных антител (МKAT) к CD-маркерам клеток: к CD3, к CD4, к CD8, к CD20 (в разведении 1/100), производства Dako (Дания) и PBS в качестве контроля для исключения пря- мого иммуномечения (окрашивания) клеток вторичными антителами и инкубировали в течение 30 минут при комнатной температуре во влажной камере. Затем стекла трижды отмывали в PBS, после чего на лунки наносили вторые связывающие антитела по 20 мкл с инкубацией 10 мин. Далее проводили трехкратную промывку стекол PBS. Затем на лунки наносили стрептавидин, конъюгированный с пероксидазой, по 20 мкл с инкубацией 10 мин. Далее трехкратно промывали стекла PBS. Приготовленный ех tempore хромоген (3-диаминобензидин тетрахлорид) наносили по 30 мкл на лунку на 10 мин. и смывали его дистиллированной водой. Стекла подсушивали [5].

Визуализацию и подсчет иммунопозитивных клеток проводили с помощью бинокулярного светового микроскопа (Axioscop «Carl Zeiss», Германия). Увеличение: объектив х100, окуляр х10. CD-позитивные клетки имели отчетливое коричневое окрашивание. Определяли среднее содержание клеток, экспрессирующих CD белки [5].

Статистическую обработку данных проводили с помощью программы Statistica 8.0. Для проверки статистических гипотез использовали t-критерий Стьюдента для зависимых и независимых выборок. Результаты представлены как среднее \pm стандартное отклонение (s). Критический уровень значимости $\mathrm{p} \leq 0,01, \mathrm{p} \leq 0,05$.

\section{Результаты \\ и обсужление}

При изучении показаний лейкограммы контрольных животных было установлено, что изучаемые показатели крови находились в пределах физиологической нормы (табл. 1) [1,2]. В тоже время в лейкограмме опытных животных наблюдались значительные изменения, что свидетельствует о воздействии свинца на клетки крови и органы лейкопоэза и демонстрирует признаки интоксикации (табл. 1). 
Таблица 2. Лейкоцитарные индексы крови у крыс $(\mathrm{M} \pm \mathrm{s})$

\begin{tabular}{|l|l|l|}
\hline Показатель, усл.ед & Контроль & Опыт \\
\hline Индекс Кребса & $0,2 \pm 0,04$ & $0,3 \pm 0,03^{*}$ \\
\hline Лейкоцитарный индекс & $3,9 \pm 0,5$ & $2,8 \pm 0,2^{*}$ \\
\hline Лейкоцитарный индекс интоксикации & $0,2 \pm 0,03$ & $0,3 \pm 0,03^{*}$ \\
\hline Индекс сдвига лейкоцитов крови & $0,3 \pm 0,04$ & $0,5 \pm 0,04^{*}$ \\
\hline Индекс соотношения лимфоцитов и моноцитов & $22,1 \pm 9,6$ & $28,1 \pm 5,0^{*}$ \\
\hline
\end{tabular}

Примечание: * - достоверно по отношению к контролю $\mathrm{P} \leq 0,01$; ${ }^{-}$- достоверно по отношению к опыту $1 \mathrm{P} \leq 0,01$.

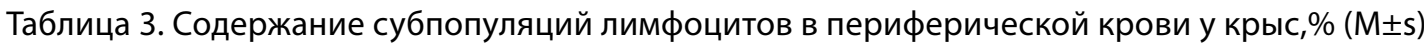

\begin{tabular}{|l|l|l|}
\hline Субпопуляция лимфоцитов & Контроль & Опыт \\
\hline CD3 & $45,1 \pm 2,6$ & $36,2 \pm 1,8^{*}$ \\
\hline CD4 & $31,7 \pm 2,5$ & $20,5 \pm 1,0^{*}$ \\
\hline CD8 & $18,4 \pm 1,4$ & $8,6 \pm 0,4^{*}$ \\
\hline CD20 & $22,0 \pm 1,3$ & $13,1 \pm 0,6^{*}$ \\
\hline
\end{tabular}

Примечание: * - достоверно по отношению к контролю $\mathrm{P} \leq 0,01$; ${ }^{*}$ - достоверно по отношению к опыту $1 \mathrm{P} \leq 0,01$.

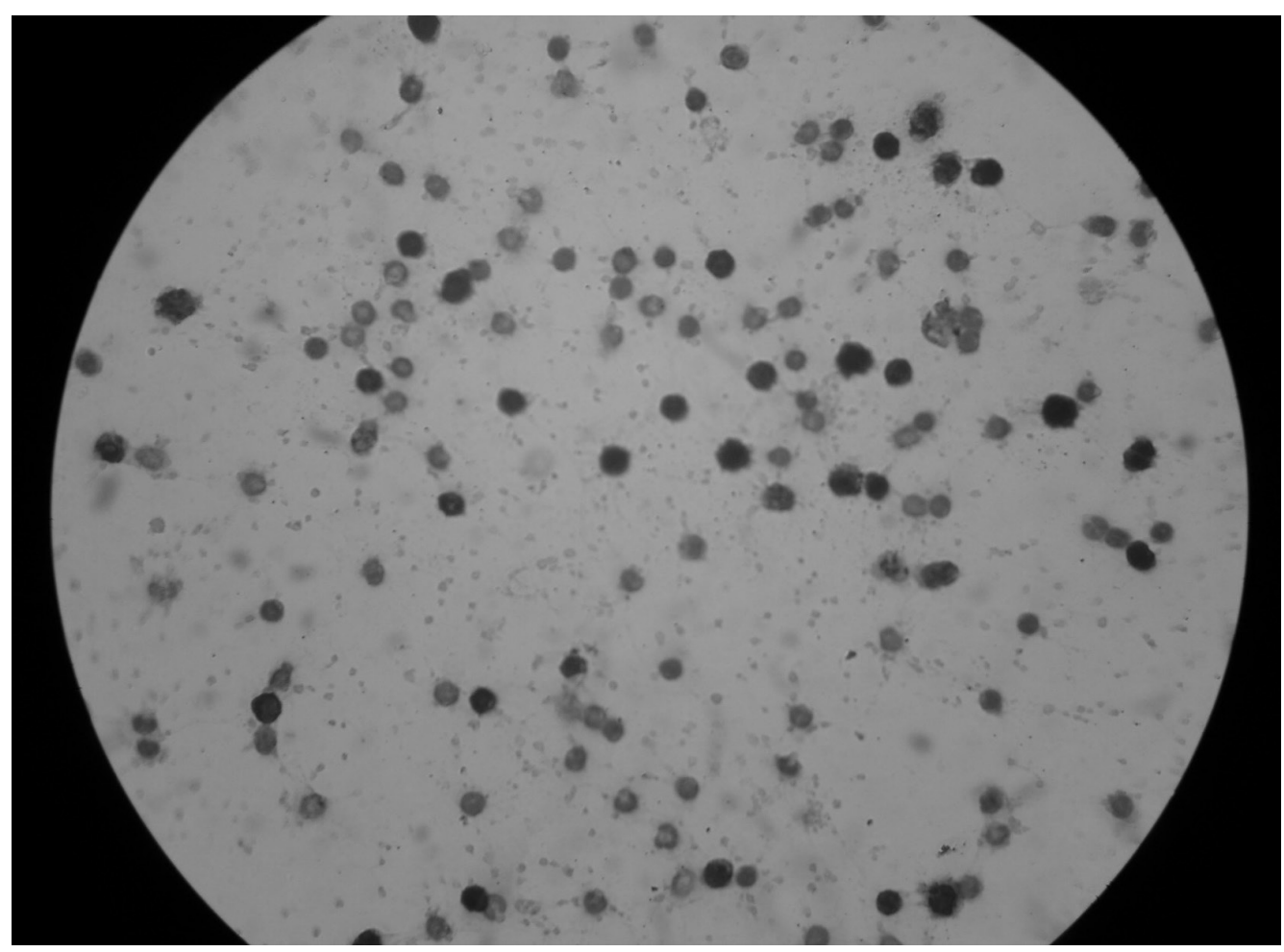

Рис. 1. Субпопуляция Т-лимфоцитов (CD3) в периферической крови у крыс (контроль). Окрашивание (иммуномечение) моноклональными антителами к CD3-маркеру клеток. Об. $100 \times$ ок. 10. 


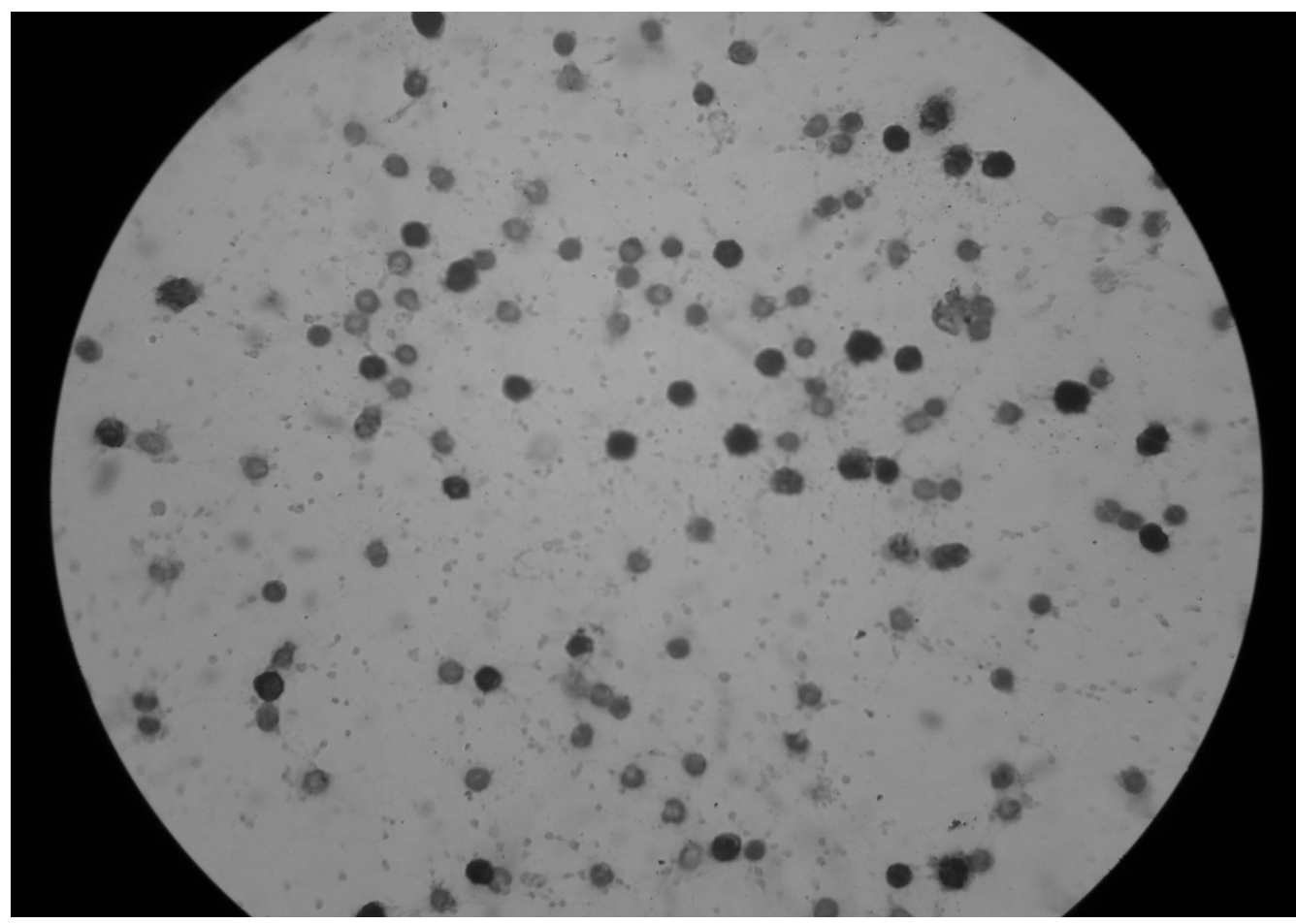

Рис. 2. Субпопуляции Т-лимфоцитов (CD3) в периферической крови у крыс (опыт 1). Окрашивание (иммуномечение) моноклональными антителами к CD3-маркеру клеток. О6. 100 × ок. 10.

В крови животных, получавших ацетат свинца, наблюдался умеренный рост общего количества лейкоцитов (на 5,2\%, p $\leq 0,01$ ). При этом произошло существенное увеличение количества палочкоядерных нейтрофилов (на $127,8 \%(\mathrm{p} \leq 0,01)$, при умеренном росте концентрации сегментоядерных (на $6,4 \%, p \leq 0,05$ ). Обращает на себя внимание резкое увеличение под влиянием свинцовой интоксикации количества эозинофилов (в 2,95 раза, $p \leq 0,01)$, при существенном уменьшении содержания базофилов (на $42,7 \%, \mathrm{p} \leq 0,01$ ), моноцитов (на $41,9 \%, p \leq 0,01$ ) и лимфоцитов (на $11 \%, p \leq 0,01$, табл. 1).

В качестве оценки интоксикации организма крыс мы провели анализ лейкоцитарных индексов, который показал, что в опытной группе по сравнению с контрольной, наблюдалось увеличение индекса Кребса (на $38,4 \%, p \leq 0,01$ ), лейкоцитарного индекса интоксикации (на 25\%, $\mathrm{p} \leq 0,01$ ), индекса сдвига лейкоцитов крови (на 61,3\%, р $\leq 0,01$ ), индекса соотношения лимфоцитов и моноцитов крови (на 26,9\%, p $\leq 0,01$ ), уменьшение лейкоцитарного индекса (на 28,8\%, p $\leq 0,01$ ), (табл. 2).

Совокупность изменения индексов указывает на течение в организме патологического процесса, сопровождающегося разрушением и сбоем в работе иммунной системы. Это выразилось в стойком повышении пока- заний всех индексов, за исключением лейкоцитарного, величина которого понизилась вследствие увеличения относительного содержания нейтрофилов.

При оценивании экспрессии маркеров CD3, CD4, CD8, характеризующих работу Т-клеточного звена циркулирующих лимфоцитов так же был обнаружен ряд изменений в сравнении с показаниями контрольной группы животных (табл. 3).

Отмечалось уменьшение содержания CD3, CD4, CD8-лимфоцитов на 20\%, 35\%, 53\% (p $\leq 0,01)$. Полученные данные свидетельствуют о возникновении иммунодефицита по клеточному типу, ослабевании цитотоксической и супрессорной функций.

При оценивании работы В-системы иммунитета основным определяемым маркером В-лимфоцитов являлся CD20. В сравнении с показателями контрольной группы, в опытной группе отмечалось снижение CD20-лимфоцитов на 40\% ( $\leq \leq 0,01)$, что указывает на нарушения в работе гуморального иммунитета и нарушение продукции антител (табл. 3).

\section{Выво $\Delta ы$}

Получение крысами течение 7 суток перорально ацетат свинца $\mathrm{Pb}\left(\mathrm{CH}_{3} \mathrm{COO}\right)_{2} \times 3 \mathrm{H}_{2} \mathrm{O}$ в дозе $45 \mathrm{mг} / \mathrm{kг} /$ сут- 
ки привело к резким изменениям в лейкоцитарной формуле: более чем двукратному росту числа палочкоядерных нейтрофилов и еще более значительному увеличению содержания эозинофилов при существенном снижении относительного содержания базофилов и лимфоцитов.
Так же, у животных опытной группы отмечались изменения, в лейкоцитарных индексах, содержании CD3, CD4, CD8, CD20-лимфоцитов, указывающие на протекание патологических процессов, нарушение работы клеточного и гуморального звеньев иммунитета, угнетение иммунореактивности, вызванные действием ацетата свинца.

\section{ЛИТЕРАТУРА}

1. Бышевский, А.Ш. Неспецифическая коррекция изменений гемостаза при заболеваниях, протекающих с гиперкоагуляцией /А.Ш. Бышевский, С.J. Галян, В.А. Полякова // Фундаментальные исследования.-2008. — № 2.— С. 29-36.

2. Васильев, Ю.Г. Ветеринарная клиническая гематология / Ю.Г. Васильев // Учебное пособие. Гриф Ум0 вузов России (+ DVD/ Лань, 2020.—687 c.

3. Дубынин, В.А. Регуляторные системы организма человека: учеб. пособие для студ. вузов / В.А. Дубынин, А.А. Каменский, М.Р. Сапин.- М.: Дрофа, 2010. - 365 c.

4. Кобец, Т.В. Интегральные лейкоцитарные индексы как критерий оценки тяжести течения эндогенной интоксикации и эффективности проводимого лечения у детей с атопическим дерматитом [Электронный ресурс] / Т.В. Кобец [и др.] // От научных разработок к внедрению в практику: педиатрия и детская хирургия: материалы VI Всерос. науч.-практ. конф., 4-5 окт. 2012 г. / под ред. Т.И. Текученко; КГмУ им. С.И. Георгиевского.-Алушта, 2012.— - Режим доступа: URL: http://drcobez.narod.ru/st

5. Семченко, В.В. Гистологическая техника: учебное пособие / В.В. Семченко, С.А. Барашкова, В.И. Ноздрин, В.Н. Артемьев.- 0мск-0рел: 0мская областная типография. - 2006. - 290 c.

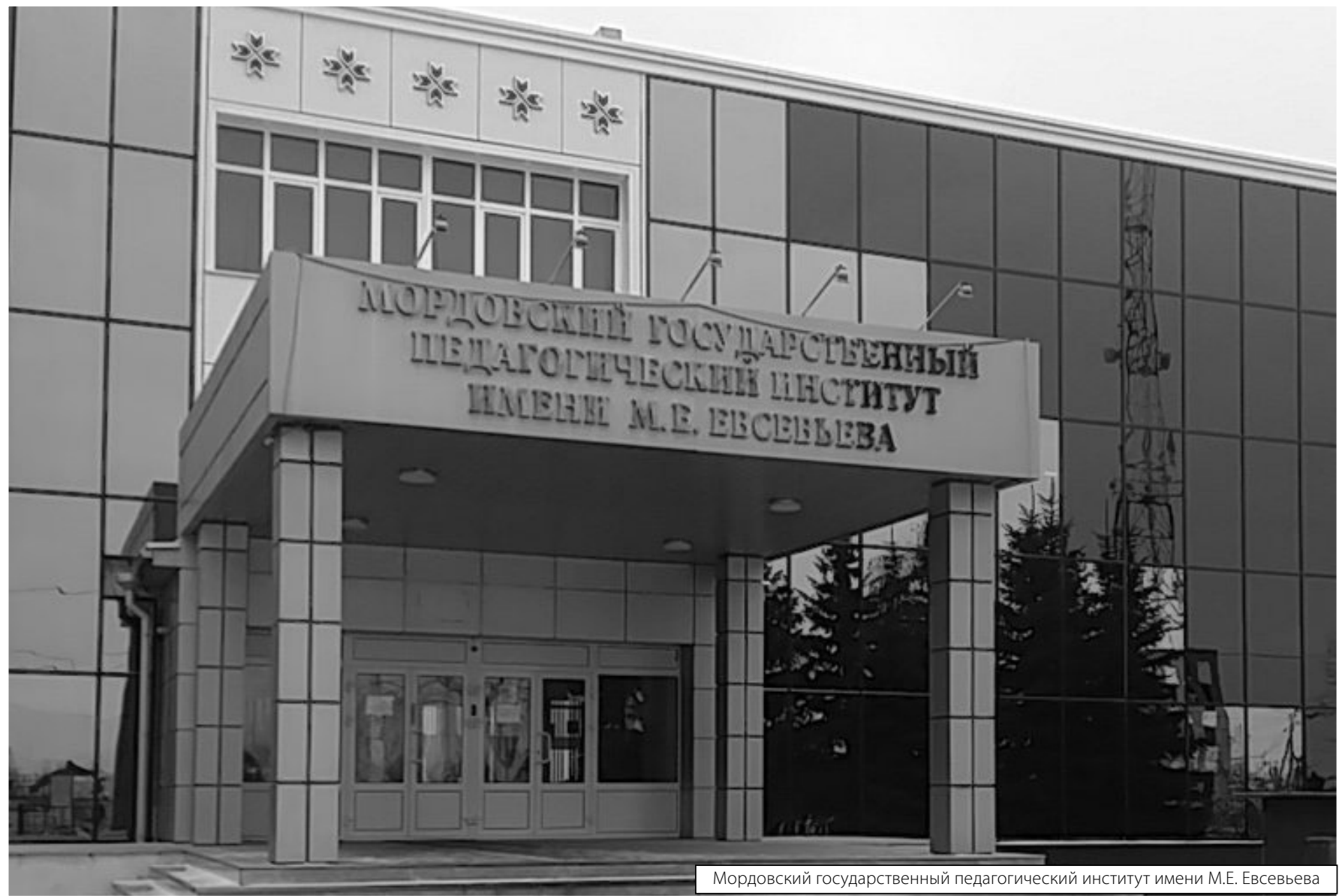

